\title{
Slaughter pigs as carrier of Listeria monocytogenes in Germany
}

\author{
Verena Oswaldi $^{1}\left[\right.$. Janine Dzierzon ${ }^{1} \cdot$ Susann Thieme ${ }^{1} \cdot$ Roswitha Merle $^{2} \cdot$ Diana Meemken $^{1}$
}

Received: 14 December 2020 / Revised: 4 March 2021 / Accepted: 23 March 2021 / Published online: 22 April 2021

(c) The Author(s) 2021

\begin{abstract}
Listeria (L.) monocytogenes as the cause of human listeriosis is widespread in the environment and a hazard considering food safety. Almost all animal species as well as humans can be asymptomatic carriers of this bacterium. In pigs, the tonsils are identified as the organ with the highest detection rate compared to other sample matrices. We sampled 430 pigs in total in two slaughterhouses in Northwest and East Germany, two structurally different and important regions in pig production, to re-examine pigs as a possible source of Listeria-contamination of pork products. We detected a low prevalence of $L$. monocytogenes in tonsil samples of 1.6\% (7/430) on single animal level and of 11.6\% (5/43) on herd level with no significant difference between the two German regions. Apart from L. monocytogenes, the usually non-pathogenic L. innocua had a prevalence of $1.2 \%$ (5/430) on single animal level. From 200 pigs from Northwest Germany, intestinal content samples were analysed in addition to tonsil samples from the same animals, but no positive sample was found for L. monocytogenes $(0.0 \%, 0 / 200)$, while four pigs were positive for L. innocua $(2.0 \%, 4 / 200)$. Although the prevalence of $L$. monocytogenes in tonsils is low, the risk of cross-contaminating meat with the pathogen is still given.
\end{abstract}

Keywords Listeria monocytogenes $\cdot$ Abattoir $\cdot$ Pig tonsils $\cdot$ Pig intestinal content $\cdot$ Asymptomatic carrier $\cdot$ Slaughter hygiene

\section{Introduction}

Listeria (L.) monocytogenes as the most important human pathogenic species of the genus Listeria is the causative agent of the rare but severe human listeriosis (Allerberger and Wagner 2010). There are 20 recognized species of the genus Listeria, and apart from L. monocytogenes, the species L. ivanovii is also considered a pathogen (Leclercq et al. 2019). L. innocua is considered to be non-pathogenic, although there are rare reports of disease caused by atypical hemolytic L. innocua strains (Moura et al. 2019; Perrin et al. 2003).

Human listeriosis can manifest in a non-invasive gastrointestinal form in immunocompetent persons or in an invasive form in young, old, immunocompromised or pregnant

Verena Oswaldi

verena.oswaldi@fu-berlin.de

1 Working Group Meat Hygiene, Institute of Food Safety and Food Hygiene, Freie Universität Berlin, Berlin, Germany

2 Institute for Veterinary Epidemiology and Biostatistics, Freie Universität Berlin, Berlin, Germany patients with symptoms like meningitis, encephalitis, sepsis, perinatal infections and abortions (Allerberger and Wagner 2010). In 2019, the incidence of human listeriosis in Germany was 0.7 cases per 100,000 people with a case fatality rate of 7\% (Robert Koch-Institut 2020). In the European Union, the case fatality rate is even higher (16\%) which makes listeriosis one of the most serious foodborne diseases with 14 reported foodborne outbreaks in 2018 (EFSA and ECDC 2019).

L. monocytogenes is frequently found in food products of animal origin such as processed meat, fish and dairy products, but also in vegetable products (Desai et al. 2019). In particular, pork meat was linked to several outbreaks of listeriosis (Duranti et al. 2018; Pichler et al. 2009). Next to raw and unprocessed food products, also processed and heattreated products that have been contaminated after heating bear a particular risk for causing an infection (Ramaswamy et al. 2007).

The resilient bacterium L. monocytogenes is ubiquitous in the environment. It has been isolated from soil, dust, water, feed and sewage and from almost any animal species, including asymptomatic humans (Allerberger 2007). In asymptomatic pigs, it has been found in several matrices 
including intestinal content, tonsils, lymph nodes, pluck sets and carcass swabs, while tonsils showed the highest prevalence (Fredriksson-Ahomaa et al. 2009; Hellström et al. 2010; Iida et al. 1998; Kanuganti et al. 2002; Sarno et al. 2016). In rare cases it can also cause clinical disease in pigs (Stein et al. 2018).

Feed is described as the main source of contamination with Listeria, but also an environmental source is possible due to the soil origin of Listeria spp. (Beloeil et al. 2003; Skovgaard and Nørrung 1989).

For South Germany, Fredriksson-Ahomaa et al. (2009) found prevalence rates for L. monocytogenes of $32 \%$ (16/50) in tonsils and 4\% (2/50) in feces originating from pigs.

The aim of the present study was to get a first overview of the current status of contamination in pig herds with $L$. monocytogenes in two other important and structurally different pig production regions of Germany, the Northwest and the East, to reconsider pigs as a possible source of contamination of pork products. Compared to South of Germany, where farms are small but numerous, there are many large farms and a very high production animal density in the Northwest of Germany, whereas the East has few very large farms. Numerically, $43 \%$ of fattening pig farms keeping $19 \%$ of total German fattening pigs are located in the South. In the Northwest, there are $29 \%$ of German fattening pig farms which are keeping $56 \%$ of fattening pigs, while $5 \%$ of German fattening pig farms keeping $11 \%$ of fattening pigs are located in the East (Merle et al. 2012). The two different regions were chosen to examine if differences in agricultural structure have an effect on the L. monocytogenes contamination of pig herds.

\section{Materials and methods}

The samples were taken from conventionally raised fattening pigs of 6-7 months of age in two industrial slaughterhouses. The slaughter capacity of both slaughterhouses amounts to more than 5000 pigs per day. The slaughterhouses as well as the fattening pig farms are located in Germany in two regions with different agricultural structures. The Northwest is characterized as a high pig dense region with many large sized pig farms whereas the East stands for a low pig dense region with a few but huge pig farms.

In slaughterhouse A, tonsil as well as intestinal content samples from 200 slaughter pigs from 20 farms, i.e. ten pigs per farm, were taken on four different dates in winter 2018/2019. The randomly chosen farms raise at least 1000 pigs per year and are located in Northwest Germany. We selected every third pig of each chosen herd, till attaining ten pigs. In order to get both samples from the same animal, one person labelled the chosen pigs before evisceration. Samples of tonsils were taken using sterile forceps and disposable scalpels (Cutfix ${ }^{\circledR}$; B.Braun, Melsungen, Germany) after the splitting of carcasses and were stored in sterile stomacher bags (VWR ${ }^{\circledR}$ Blender Bag; Radnor, PA, USA). In slaughterhouse $\mathrm{A}$, the carcasses were split along the midline from back to front inclusively their heads. Intestinal content from the same animals were taken into a $15 \mathrm{ml}$ fecal tube (Carl Roth GmbH, Karlsruhe, Germany) after evisceration by incising the correspondent rectum with a sterile scalpel.

Due to negative results for $L$. monocytogenes in fecal samples in slaughterhouse A, no fecal samples were taken in slaughterhouse B. The sampling in slaughterhouse B was performed in autumn 2019. Samples from 180 pigs originating from 18 farms located in East Germany and 50 pigs originating from five farms located in Northwest Germany were taken. Therefore, from each randomly selected farm, ten pigs were randomly chosen and their tonsils were cut out with a disposable scalpel and a sterile forceps directly at the end of the slaughter line and stored in sterile stomacher bags. This slaughterhouse used automatic splitting with saws splitting exclusively the heads of the carcasses.

All samples were transported in cold storage between 2 and $8{ }^{\circ} \mathrm{C}$ directly into the institute's laboratory and examination started the following day.

Processing of the samples was performed in accordance to the EN ISO 11290-1:2017 protocol (Horizontal method for the detection and enumeration of Listeria monocytogenes and of Listeria spp.) with minor modifications: samples of tonsils weighed $12 \mathrm{~g}$ on average, whereas samples of intestinal content weighed $1-2 \mathrm{~g}$. They were homogenized in a stomacher (Smasher ${ }^{\mathrm{TM}}$ High-Performance Blender/Homogenizer, bioMerieux, Marcy-l'Étoile, France) for 2 min with half-Fraser broth (Merck KGaA, Darmstadt, Germany) in a dilution of 1:10. The homogenate was incubated for $24 \mathrm{~h}$ at a temperature of $30{ }^{\circ} \mathrm{C}$. Altogether, $0.1 \mathrm{ml}$ of the incubated suspension was mixed in $10.0 \mathrm{ml}$ Fraser broth (Merck KGaA, Darmstadt, Germany) and incubated for $24 \mathrm{~h}$ at $37^{\circ} \mathrm{C}$, followed by streaking out on two selective agar plates. Those selective agar plates were Agar Listeria according to Ottaviani and Agosti (ALOA; Merck KGaA, Darmstadt, Germany) and PALCAM agar (Merck KGaA, Darmstadt, Germany). The agar plates were incubated at $37{ }^{\circ} \mathrm{C}$ for $48 \mathrm{~h}$. Presumptive colonies were streaked out on Columbia blood agar (Oxoid Ltd., Hampshire, UK) and incubated for $24 \mathrm{~h}$ at $37^{\circ} \mathrm{C}$, followed by a CAMP test, catalase test, biochemical tests including rhamnose and xylose sugar utilization and Gram staining in accordance with the EN ISO 11290-1:2017. As confirmation, a multiplex polymerase chain reaction (PCR) as described by Bubert et al. (1999) was performed, firstly to confirm the Genus Listeria and secondly to verify the species. The cycling conditions were $95{ }^{\circ} \mathrm{C}$ for $5 \mathrm{~min}$ for the initial denaturation, followed by $95{ }^{\circ} \mathrm{C}$ for $15 \mathrm{~s}$ (denaturation), $58^{\circ} \mathrm{C}$ for $30 \mathrm{~s}$ annealing, $72{ }^{\circ} \mathrm{C}$ for $50 \mathrm{~s}$ (extension) and $72{ }^{\circ} \mathrm{C}$ for $5 \mathrm{~min}$ as a final step. 
Table 1 Results in samples of tonsils in \% (n/N) (95\% CI confidence interval)

\begin{tabular}{clll}
\hline & $\begin{array}{l}\text { Detection rate } \\
\text { of Listeria spp. } \\
(95 \% \mathrm{CI})\end{array}$ & $\begin{array}{l}\text { Detection rate } \\
\text { of L. monocy- } \\
\text { togenes } \\
(95 \% \mathrm{CI})\end{array}$ & $\begin{array}{l}\text { Detection rate } \\
\text { of L. innocua } \\
(95 \% \mathrm{CI})\end{array}$ \\
\hline Total & $2.8 \%(12 / 430)$ & $1.6 \%(7 / 430)$ & $1.2 \%(5 / 430)$ \\
Slaughterhouse & $1.5 \%(3 / 200)$ & $1.0 \%(2 / 200)$ & $0.5 \%(1 / 200)$ \\
A & $(0.00-3.18 \%)$ & $(0.00-2.38 \%)$ & $(0.00-1.48 \%)$ \\
Slaughterhouse & $4.4 \%(8 / 180)$ & $2.8 \%(5 / 180)$ & $1.7 \%(3 / 180)$ \\
$\mathrm{B}^{\mathrm{a}}$ & $(1.43-7.46 \%)$ & $(0.38-5.18 \%)$ & $(0.00-3.54 \%)$ \\
Slaughterhouse & $2.0 \%(1 / 50)$ & $0.0 \%(0 / 50)$ & $2.0 \%(1 / 50)$ \\
$\mathrm{B}^{\mathrm{b}}$ & $(0.00-5.88 \%)$ & $(0.00-6.98 \%)$ & $(0.00-5.88 \%)$ \\
\hline
\end{tabular}

${ }^{a}$ Samples of pigs from East Germany

${ }^{\mathrm{b}}$ Samples of pigs from Northwest Germany

Species identification was also confirmed by matrix-assisted laser desorption-ionization-time of flight mass spectrometry (MALDI-TOF MS) (Bruker MALDI Biotyper ${ }^{\circledR}$; Bruker Daltonik, Bremen, Germany).

Calculation of sample size was based on an expected prevalence between 4 and 30\% according to previous studies in Germany and other European countries within the last 15 years (Fredriksson-Ahomaa et al. 2009; Hellström et al. 2010; Sarno et al. 2016). We tested 200 and 230 animals per slaughterhouse, respectively for an accuracy of 5-10\%. The Chi-square-test and odds ratio were performed with IBM $^{\circledR}$ SPSS ${ }^{\circledR}$ Statistics Version 25 (SPSS, Inc., Chicago, IL) with $p \leq 0.05$ defined as statistically significant. The $95 \%$ confidence intervals (95\% CI) were calculated using epitools ${ }^{1}$ and causascientia $^{2}$ if the result was zero.

\section{Results}

In tonsil samples, the detection rate for Listeria spp. was $2.8 \%$ (12/430) on single animal basis (Table 1). The detection rate of $L$. monocytogenes was $1.6 \%$ (7/430). In slaughterhouse A, three out of 200 pigs $(3 / 200,1.5 \%)$ originating from Northwest Germany were positive for Listeria spp. in tonsil samples. In detail, two samples were positive for $L$. monocytogenes $(2 / 200,1.0 \%)$ and one for $L$. innocua $(1 / 200$, $0.5 \%)$. All affected animals originated from different farms. In intestinal content samples, four animals from four different farms were tested positive for L. innocua (Table 2). None of these animals showed positive results in tonsils.

\footnotetext{
1 https://epitools.ausvet.com.au/ciproportion Accessed March 2021.

2 https://www.causascientia.org/math_stat/ProportionCI.html Accessed March 2021.
}

Table 2 Results in samples of intestinal content in \% (n/N) (95\% CI)

\begin{tabular}{clll}
\hline & $\begin{array}{l}\text { Detection rate } \\
\text { of Listeria spp. } \\
(95 \% \mathrm{CI})\end{array}$ & $\begin{array}{l}\text { Detection rate } \\
\text { of L. monocy- } \\
\text { togenes } \\
(95 \% \mathrm{CI})\end{array}$ & $\begin{array}{l}\text { Detection rate of } \\
\text { L. innocua } \\
(95 \% \mathrm{CI})\end{array}$ \\
\hline $\begin{array}{l}\text { Slaughterhouse } \\
\text { A }\end{array}$ & $\begin{array}{l}2.0 \%(4 / 200) \\
(0.06-3.94 \%)\end{array}$ & $\begin{array}{l}0.0 \%(0 / 200) \\
(0.00-1.82 \%)\end{array}$ & $\begin{array}{l}2.0 \%(4 / 200) \\
(0.06-3.94 \%)\end{array}$ \\
\hline
\end{tabular}

No intestinal content sample taken in slaughterhouse B

In slaughterhouse B, out of 180 pigs from East Germany, eight samples $(8 / 180,4.4 \%)$ were positive for Listeria spp. Five of those isolates were confirmed as L. monocytogenes $(5 / 180,2.8 \%)$ and three as $L$. innocua $(3 / 180,1.7 \%)$. These five $L$. monocytogenes positive samples originated from three farms with three isolates from pigs of the same farm and the other two from two different farms, respectively. In addition, the three isolates of $L$. innocua came from one single farm - a farm with no L. monocytogenes positive samples. From 50 pig tonsil samples from Northwest Germany slaughtered in slaughterhouse B, L. innocua was found in one sample $(1 / 50,2.0 \%)$.

A herd with at least one positive tonsil sample was regarded positive. The total herd level detection rate was $16.3 \%$ (7/43) for Listeria spp. and $11.6 \%$ (5/43) for L. monocytogenes (Table 3). Considering only results of intestinal content samples, the herd detection rate of Listeria spp. was $20.0 \%(4 / 20)$ and of $L$. monocytogenes $0.0 \%(0 / 20)$ in slaughterhouse A (Table 4).

To compare the results of pigs tested in both slaughterhouses, the samples of intestinal content in slaughterhouse A were omitted in the following results: the herd detection rate in slaughterhouse A was $10.0 \%$ (2/20) for Listeria spp. as well as for L. monocytogenes. In slaughterhouse B, the herd detection rate for Listeria spp. was $21.7 \%(5 / 23)$ and for $L$. monocytogenes $13.0 \%$ (3/23). The Chi-square-test showed no statistically significant association $(p=0.420$ for Listeria spp. resp. $p>0.999$ for L. monocytogenes) of slaughterhouse and the finding of positive herds, as though the odds ratio showed a 2.5 (95\% CI 0.428-14.607) resp. 1.4 (95\% CI 0.202-9.018) times higher risk to find a positive pig herd in slaughterhouse B. Altogether, in tested pig herds originating from Northwest Germany the herd detection rate was $12.0 \%$ (3/25) for Listeria spp. and 8.0\% (2/25) for $L$. monocytogenes. In pig herds originating from East Germany, the herd detection rate was $22.2 \%$ (4/18) for Listeria spp. and $16.7 \%$ (3/18) for L. monocytogenes. The odds ratio showed a 2.1 (95\% CI 0.406-10.802) resp. 2.3 (95\% CI 0.343-15.436) times higher risk for a positive herd originating from East Germany, but the Chi-square-test showed no statistically significant correlation between positive results and origin of pigs ( $p=0.427$ resp. $p=0.634$ ) in this study. 
Table 3 Results on herd level in samples of tonsils in \% $(\mathrm{n} / \mathrm{N})$ $(95 \% \mathrm{CI})$

\begin{tabular}{llll}
\hline & $\begin{array}{l}\text { Herd detection rate of } \\
\text { Listeria spp. } \\
(95 \% \mathrm{CI})\end{array}$ & $\begin{array}{l}\text { Herd detection rate of } \\
\text { L. monocytogenes } \\
(95 \% \mathrm{CI})\end{array}$ & $\begin{array}{l}\text { Herd detec- } \\
\text { tion rate of } \\
\text { L. innocua } \\
(95 \% \mathrm{CI})\end{array}$ \\
\hline Total & $16.3 \%(7 / 43)$ & $11.6 \%(5 / 43)$ & $7.0 \%(3 / 43)$ \\
Slaughterhouse A & $(5.24-27.31 \%)$ & $(2.05-21.21 \%)$ & $(0.00-14.59 \%)$ \\
Slaughterhouse B & $10.0 \%(2 / 20)$ & $10.0 \%(2 / 20)$ & $5.0 \%(1 / 20)$ \\
& $(0.00-23.15 \%)$ & $(0.00-23.15 \%)$ & $(0.00-14.55 \%)$ \\
Slaughterhouse B & $22.2 \%(4 / 18)$ & $16.7 \%(3 / 18)$ & $5.6 \%(1 / 18)$ \\
& $(3.02-41.43 \%)$ & $(0.00-33.88 \%)$ & $(0.00-16.14 \%)$ \\
& $20.0 \%(1 / 5)$ & $0.0 \%(0 / 5)$ & $20.0 \%(1 / 5)$ \\
& $(0.00-55.06 \%)$ & $(0.00-45.93 \%)$ & $(0.00-55.06 \%)$ \\
\hline
\end{tabular}

${ }^{\text {a }}$ Samples of pig herds from East Germany

${ }^{\mathrm{b}}$ Samples of pig herds from Northwest Germany
As on herd basis, also the single animal results showed no statistically significant association of the origin of pigs and positive results for Listeria spp. as well as for L. monocytogenes ( $p=0.134$ resp. $p=0.135$ ) with an odds ratio of 2.9 (95\% CI 0.848-9.650) resp. 3.5 (95\% CI 0.680-18.470).

For comparison of the specificity of culture, PCR and MALDI-TOF MS for species identification, the results for all isolates were identical with all methods.

\section{Discussion}

This study shows the first data of asymptomatic L. monocytogenes carrier pigs originating from two structurally different pig production regions in Germany, the Northwest and the East. Results of 1.6\% (7/430) positive $L$. monocytogenes tonsil samples in total assume a high hygienic standard in the corresponding farms. The diverse agricultural structures with high vs. low density and big vs. very big farms in the Northwest and East of Germany, respectively, showed no significant difference on the impact of contamination with L. monocytogenes. For South Germany, where farms are in average smaller but the density of farms is high (Merle et al. 2012), Fredriksson-Ahomaa et al. (2009) isolated L. monocytogenes in $34 \%$ of tonsils and $4 \%$ in feces of 50 slaughter pigs. Next to agricultural structures, the occurrence of $L$. monocytogenes in pigs may also be influenced by, e.g., date and method of investigations.

Other prevalence studies of $L$. monocytogenes in asymptomatic pigs in different regions of the world come to various results. In Fig. 1, results of several selected studies in comparison with our results are illustrated in reverse chronological order. The previous studies show a variation of results from $0 \%$ positive fecal samples in North Spain (Esteban et al. 2009) to $45 \%$ positive samples of tonsils in Yugoslavia (Bunčić 1991), even though a direct comparison must be seen critically because of different sampling
Table 4 Results on herd level in samples of intestinal content in \% $(\mathrm{n} / \mathrm{N})(95 \% \mathrm{CI})$

\begin{tabular}{llll}
\hline & $\begin{array}{l}\text { Herd detection } \\
\text { rate of Listeria } \\
\text { spp. } \\
(95 \% \mathrm{CI})\end{array}$ & $\begin{array}{l}\text { Herd detection } \\
\text { rate of L. mono- } \\
\text { cytogenes } \\
(95 \% \mathrm{CI})\end{array}$ & $\begin{array}{l}\text { Herd detec- } \\
\text { tion rate of } L . \\
\text { innocua } \\
(95 \% \mathrm{CI})\end{array}$ \\
\hline $\begin{array}{l}\text { Slaughterhouse } \\
\text { A }\end{array}$ & $20.0 \%(4 / 20)$ & $0.0 \%(0 / 20)$ & $20.0 \%(4 / 20)$ \\
\hline
\end{tabular}

In slaughterhouse B, no intestinal content samples weretaken

CI Confidence interval

and detection methods, sample sizes and circumstances like husbandry conditions. Considering the environmental source of L. monocytogenes, the feeding and husbandry conditions have an impact on the contamination of pigs on the farm (Skovgaard 1990). For example, pigs were partially fed with silage in the study of Bunčić (1991) what explains a higher prevalence of $L$. monocytogenes. In the study of Hellström et al. (2010) pigs from organic farms showed a higher prevalence than conventionally raised pigs in farm-level as well as at slaughterhouse level. Different feeding practices, e.g., hay or straw as coarse feed, and more contact to soil, plants and other animals lead to a higher risk of contamination with this ubiquitous pathogen. The chronological depiction of previous study results indicates a slight trend of decreasing numbers of the bacterium found in pigs. The negative correlation with the increasing numbers of human disease cases could be explained by changing of production and distribution of food which support the widespread of the pathogen. For instance, the rising popularity of ready-to-eat products, which are intended to be eaten without further heating, are one of the most important sources for human listeriosis (Kurpas et al. 2018).

As shown in Figure 1, prevalence rates from our study are comparably low. In slaughterhouse A, we detected $1.0 \%$ 


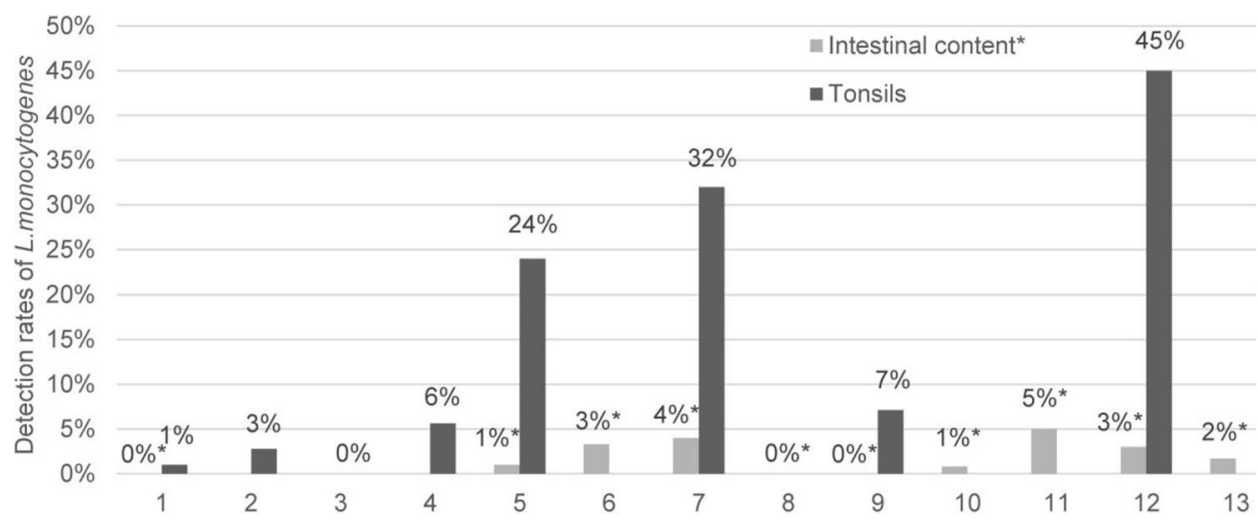

Fig. 1 Detection rates of $L$. monocytogenes in pigs found in this and in various studies worldwide in reverse chronological order. 1: Slaughterhouse A (pigs from Northwest Germany). 2: Slaughterhouse B (pigs from East Germany). 3: Slaughterhouse B (pigs from Northwest Germany). 4: Sarno et al. (2016) (Switzerland). 5: Hellström et al. (2010) (Finland). 6: Farzan et al. (2010) (Canada). 7: Fredriksson-Ahomaa et al. (2009) (South Germany). 8: Esteban et al. (2009) (Spain). 9: Kanuganti et al. (2002) (USA). 10: Iida et al. (1998) (Japan). 11: Adesiyun and Krishnan (1995) (Trinidad). 12: Bunčić (1991) (Yugoslavia). 13: Skovgaard and Nørrung (1989) (Denmark)
(2/200) of tonsil samples vs. $0.0 \%$ (0/200) intestinal content samples positive for L. monocytogenes. Results suit with the higher detection rate of this pathogen in samples of tonsils than of intestinal content from other studies (FredrikssonAhomaa et al. 2009; Hellström et al. 2010). Intestinal content taken as samples of feces would be easily accessible on the farm but is shown there to be an improper material to detect the actual number of asymptomatic carrier pigs in a herd. Therefore, the examination of tonsils in the slaughtering process should be preferred.

Results of this study confirm that especially tonsils can still be a reservoir for $L$. monocytogenes. The low prevalence indicates a minor but potential risk of cross-contamination of the bacterium from tonsils to meat or the slaughterhouse environment where L. monocytogenes could accumulate and spread along the food chain. Autio et al. (2000) found mechanical saws as source of cross-contaminating L. monocytogenes to pig carcasses. It underlines the importance of hygiene at the point of splitting the carcasses, removing tonsils and other steps in the slaughter line. An automatic saw like used in slaughterhouse B has the advantage of being cleaned with hot water after splitting a pig carcass, so there is a minor risk of cross-contaminating L. monocytogenes from one carcass to the next. More research is necessary to evaluate the difference in cross-contamination with $L$. monocytogenes between different types of saws and practices, e.g. splitting inclusively or exclusively the heads of carcasses.

Furthermore, in our study we could show an intra-farm accumulation of three $L$. monocytogenes as well as three $L$. innocua positive samples in slaughterhouse $\mathrm{B}$, revealing a transmission inside a herd or a shared origin of contamination on the farm, such as feeds. Cross-contamination in the slaughterhouse is unlikely to be the cause for it because the positive tested carcasses were not sampled one after another in the slaughter line. Due to data protection reasons, it was not possible in our study to get more detailed information about the farms to compare agricultural practices. Beloeil et al. (2003) identified wet feeding during the fattening period as well as low hygienic standards on farm as risk factors for L. monocytogenes contamination of pigs on farm level. Hellström et al. (2010) underlined the importance of hygiene conditions and added as further risk factors a large group size, contact with pet and pest animals, organic production, farm management practices like management of manure, use of coarse feed, access to outdoor areas and drinking from the trough.

\section{Conclusions}

In two high-capacity slaughterhouses, 250 pigs originating from Northwest Germany and 180 pigs from East Germany were tested for Listeria spp. in tonsils and the first 200 pigs also in intestinal contents. The rates of asymptomatic $L$. monocytogenes carrier pigs ( $1.6 \%$ in tonsil resp. $0.0 \%$ in intestinal content samples) found in this study are lower than in previous studies worldwide.

Due to the high numbers of pigs slaughtered per day in an average slaughterhouse in the concerned regions, the risk to introduce $L$. monocytogenes into the food chain is present. Especially tonsils of pigs may represent a reservoir for L. monocytogenes and slaughterhouse hygiene remains important to prevent a contamination of food products. On farm level, the feeding system, high hygiene and biosecurity standards are important to decrease the risk of contamination of pigs. Furthermore, differences in agricultural structures such as the high vs. low density of pig farms in Northwest 
and East Germany, respectively, had no significant impact on the prevalence rates of asymptomatic $L$. monocytogenes carrier pigs in our study.

Acknowledgements The authors would like to thank the slaughterhouses for their collaboration in sample taking and the Institute for Animal Hygiene and Environmental Health, FU Berlin for the opportunity of using their MALDI-TOF MS. Thanks to the QS science fund for funding this study.

Author contributions DM conceived the first study conception. All other authors contributed to the final study conception and design. Material preparation, data collection and analysis were performed by VO and JD. The first draft of the manuscript was written by VO and all authors commented on previous versions of the manuscript. All authors read and approved the final manuscript.

Funding Open Access funding enabled and organized by Projekt DEAL. This study was funded by the QS Qualität und Sicherheit $\mathrm{GmbH}$ science fund (Freie Universität Berlin Contract Number: 2018000308)

\section{Declarations}

Conflict of interest The authors declare that they have no conflict of interest.

Open Access This article is licensed under a Creative Commons Attribution 4.0 International License, which permits use, sharing, adaptation, distribution and reproduction in any medium or format, as long as you give appropriate credit to the original author(s) and the source, provide a link to the Creative Commons licence, and indicate if changes were made. The images or other third party material in this article are included in the article's Creative Commons licence, unless indicated otherwise in a credit line to the material. If material is not included in the article's Creative Commons licence and your intended use is not permitted by statutory regulation or exceeds the permitted use, you will need to obtain permission directly from the copyright holder. To view a copy of this licence, visit http://creativecommons.org/licenses/by/4.0/.

\section{References}

Adesiyun AA, Krishnan C (1995) Occurrence of Yersinia enterocolitica O:3, Listeria monocytogenes O:4 and thermophilic Campylobacter spp. in slaughter pigs and carcasses in Trinidad. Food Microbiol 12:99-107. https://doi.org/10.1016/S0740-0020(95) 80085-9

Allerberger F (2007) Listeria. In: Simjee S (ed) Foodborne diseases. Humana Press, Totowa, pp 27-39

Allerberger F, Wagner M (2010) Listeriosis: a resurgent foodborne infection. Clin Microbiol Infect 16:16-23. https://doi.org/10. 1111/j.1469-0691.2009.03109.x

Autio T, Säteri T, Fredrikksson-Ahomaa M, Rahkio M, Lundén J, Korkeala H (2000) Listeria monocytogenes contamination pattern in pig slaughterhouses. J Food Prot 63:1438-1442. https:// doi.org/10.4315/0362-028X-63.10.1438

Beloeil P-A, Chauvin C, Toquin M-T, Fablet C, Le Nôtre Y, Salvat G, Madec F, Fravalo P (2003) Listeria monocytogenes contamination of finishing pigs: an exploratory epidemiological survey in France. Vet Res 34:737-748. https://doi.org/10.1051/vetres:2003031
Bubert A, Hein I, Rauch M, Lehner A, Yoon B, Goebel W, Wagner M (1999) Detection and differentiation of Listeria spp. by a single reaction based on multiplex PCR. Appl Environ Microbiol 65:4688-4692

Bunčić S (1991) The incidence of Listeria monocytogenes in slaughtered animals, in meat, and in meat products in Yugoslavia. Int J Food Microbiol 12:173-180. https://doi.org/10.1016/01681605(91)90067-Y

Desai AN, Anyoha A, Madoff LC, Lassmann B (2019) Changing epidemiology of Listeria monocytogenes outbreaks, sporadic cases, and recalls globally: a review of ProMED reports from 1996 to 2018. Int J Infect Dis 84:48-53. https://doi.org/10.1016/j.ijid. 2019.04.021

Duranti A, Sabbatucci M, Blasi G, Acciari VA, Ancora M, Bella A, Busani L, Centorame $\mathrm{P}$, Cammà $\mathrm{C}$, Conti $\mathrm{F}$, de Medici D, Di Domenico M, Di Marzio V, Filippini G, Fiore A, Fisichella S, Gattuso A, Gianfranceschi M, Graziani C, Guidi F, Marcacci M, Marfoglia C, Neri D, Orsini M, Ottaviani D, Petruzzelli A, Pezzotti P, Rizzo C, Ruolo A, Scavia G, Scuota S, Tagliavento G, Tibaldi A, Tonucci F, Torresi M, Migliorati G, Pomilio F (2018) A severe outbreak of listeriosis in central Italy with a rare pulsotype associated with processed pork products. J Med Microbiol 67:1351-1360. https://doi.org/10.1099/jmm.0.000785

EFSA and ECDC (2019) The European Union one health 2018 zoonoses report. EFSA J 17(12):5926. https://doi.org/10.2903/j.efsa. 2019.5926

Esteban JI, Oporto B, Aduriz G, Juste RA, Hurtado A (2009) Faecal shedding and strain diversity of Listeria monocytogenes in healthy ruminants and swine in Northern Spain. BMC Vet Res. https://doi.org/10.1186/1746-6148-5-2

Farzan A, Friendship RM, Cook A, Pollari F (2010) Occurrence of Salmonella, Campylobacter, Yersinia enterocolitica, Escherichia coli $\mathrm{O} 157$ and Listeria monocytogenes in swine. Zoonoses Public Health 57:388-396. https://doi.org/10.1111/j.1863-2378. 2009.01248.x

Fredriksson-Ahomaa M, Gerhardt M, Stolle A (2009) High bacterial contamination of pig tonsils at slaughter. Meat Sci 83:334-336. https://doi.org/10.1016/j.meatsci.2009.06.004

Hellström S, Laukkanen R, Siekkinen K-M, Ranta J, Maijala R, Korkeala H (2010) Listeria monocytogenes contamination in pork can originate from farms. J Food Prot 73:641-648. https:// doi.org/10.4315/0362-028X-73.4.641

Iida T, Kanzaki M, Nakama A, Kokubo Y, Maruyama T, Kaneuchi C (1998) Detection of Listeria monocytogenes in humans, animals and foods. J Vet Med Sci 60:1341-1343. https://doi.org/ 10.1292/jvms.60.1341

Kanuganti SR, Wesley IV, Reddy PG, McKean J, Hurd HS (2002) Detection of Listeria monocytogenes in pigs and pork. J Food Prot 65:1470-1474. https://doi.org/10.4315/0362-028X-65.9. 1470

Kurpas M, Wieczorek K, Osek J (2018) Ready-to-eat meat products as a source of Listeria monocytogenes. J Vet Res 62:49-55. https:// doi.org/10.2478/jvetres-2018-0007

Leclercq A, Moura A, Vales G, Tessaud-Rita N, Aguilhon C, Lecuit M (2019) Listeria thailandensis sp. nov. Int J Syst Evol Microbiol 69:74-81. https://doi.org/10.1099/ijsem.0.003097

Merle R, Busse M, Rechter G, Meer U (2012) Regionalisierung Deutschlands anhand landwirtschaftlicher Strukturdaten. Berl Munch Tierarztl Wochenschr 125:52-59. https://doi.org/10.2376/ 0005-9366-125-52

Moura A, Disson O, Lavina M, Thouvenot P, Huang L, Leclercq A, Fredriksson-Ahomaa M, Eshwar AK, Stephan R, Lecuit M (2019) Atypical hemolytic Listeria innocua isolates are virulent, albeit less than Listeria monocytogenes. Infect Immun. https://doi.org/ 10.1128/IAI.00758-18 
Perrin M, Bemer M, Delamare C (2003) Fatal case of Listeria innocua bacteremia. J Clin Microbiol 41:5308-5309. https://doi.org/10. 1128/JCM.41.11.5308-5309.2003

Pichler J, Much P, Kasper S, Fretz R, Auer B, Kathan J, Mann M, Huhulescu S, Ruppitsch W, Pietzka A, Silberbauer K, Neumann C, Gschiel E, de Martin A, Schuetz A, Gindl J, Neugschwandtner E, Allerberger F (2009) An outbreak of febrile gastroenteritis associated with jellied pork contaminated with Listeria monocytogenes. Wien Klin Wochenschr 121:149-156. https://doi.org/10. 1007/s00508-009-1137-3

Ramaswamy V, Cresence VM, Rejitha JS, Lekshmi MU, Dharsana KS, Prasad SP, Vijila HM (2007) Listeria-review of epidemiology and pathogenesis. J Microbiol Immunol Infect 40:4-13

Robert Koch-Institut (2020) Infektionsepidemiologisches Jahrbuch meldepflichtiger Krankheiten für 2019

Sarno E, Fierz L, Zweifel C, Tasara T, Stephan R (2016) Characteristics of Listeria monocytogenes isolated from tonsils of slaughtered fattening pigs in Switzerland. J Verbr Lebensm 11:19-23. https:// doi.org/10.1007/s00003-015-0974-4

Skovgaard N (1990) The impact of the prevalence of Listeria monocytogenes in the environment on meat and milk hygiene. Microbiol Aliments Nutr 8:15-20

Skovgaard N, Nørrung B (1989) The incidence of Listeria spp. in faeces of Danish pigs and in minced pork meat. Int J Food Microbiol 8:59-63. https://doi.org/10.1016/0168-1605(89)90080-9

Stein H, Stessl B, Brunthaler R, Loncaric I, Weissenböck H, Ruczizka U, Ladinig A, Schwarz L (2018) Listeriosis in fattening pigs caused by poor quality silage - a case report. BMC Vet Res 14:362. https://doi.org/10.1186/s12917-018-1687-6

Publisher's Note Springer Nature remains neutral with regard to jurisdictional claims in published maps and institutional affiliations. 